\title{
Female novelty and the courtship behavior of male guinea pigs (Cavia porcellus)
}

D.W.H. Cohn,

R.S. Tokumaru and C. Ades
Departamento de Psicologia Experimental, Instituto de Psicologia, Universidade de São Paulo, São Paulo, SP, Brasil

\section{Correspondence \\ C. Ades \\ Instituto de Psicologia, USP \\ Av. Prof. Mello Moraes, 1721 \\ 05508-900 São Paulo, SP \\ Brasil \\ E-mail: cades@usp.br}

Publication supported by FAPESP.

$\ldots \ldots \ldots \ldots \ldots \ldots$

Received December 16, 2002 Accepted February 16, 2004 $\ldots \ldots \ldots \ldots \ldots \ldots \ldots$

\begin{abstract}
In several rodent species, an increase or recovery of sexual behavior can be observed when sexually satiated males are placed in contact with a novel mate. In order to assess the influence of female novelty on the courtship behavior of guinea pigs (Cavia porcellus), four adult males were observed during four daily 15 -min sessions while interacting with the same pregnant female (same-female sessions). A new female was presented during the fifth session (switched-female session). The duration of behavioral categories was obtained from videotape records using an observational software. From the first to the second session, all males decreased the time allocated to investigating (sniffing and licking), following, and mounting the female, and that response did not recover by the end of the same-female sessions. No similar decreasing tendencies were detected in the circling or rumba categories. A marked increase of investigating occurred in all males from the last same-female session $(8.1,11.9,15.1$ and 17.3 percent session time) to the switched-female one (16.4, 18.4, 37.1 and 28.9 percent session time, respectively). Increases in following and circling were recorded in three of four males, and full-blown recovery of mounting in one male. No consistent changes in the females' responses to males (following or attacking) were observed throughout testing. These results are consistent with the hypothesis that guinea pig males recognize individual females and that courtship responses may suffer a habituation/recovery process controlled by mate novelty.
\end{abstract}

The reproductive system of guinea pigs (Cavia porcellus) is a polygynic one, characterized by a high readiness of males to court females, even pregnant ones. Male courtship behavior, as observed in colonies, includes social exploration, persistently following the female and, when in close contact, a swinging movement of the posterior part of the body, the rumba (1), associated with the
Key words - Courtship behavior

- Female novelty

- Cavia porcellus
- Guinea pigs emission of a characteristically low-pitched vocalization, the purr $(2,3)$. Dominant males monopolize females and, in large groups subdivided into subunits, may establish longlasting social bonding with the females of their subunits (4-6). Individual recognition and bonding play an important role in the guinea pigs' social life and may contribute to the stability of social structure and to the 
reduction of stress (6). The neuroendocrine stress response of male guinea pigs when placed in an unfamiliar enclosure is sharply reduced when a bonded female is present but little affected by the presence of a strange female or by the presence of a familiar, nonbonded female (7).

Social experience thus seems to be quite important for the structuring of a male guinea pig's social and sexual behavior $(6,8)$. An interesting question is whether courtship behavior is under the control of the female's novelty. In several rodent species such as hamsters $(9,10)$ and rats $(11)$, but not in monogamous prairie voles (12), an increase or recovery of sexual behavior can be observed in sexually satiated males when placed in contact with a novel receptive mate, the so-called Coolidge effect.

Instead of exposing a male guinea pig to an individual female until sexual satiation is reached, then assessing the male's reaction to the immediate introduction of a novel female according to the classical Coolidge model, in the present study we adopted a schedule in which the same female was presented during four 15-min sessions per day, being switched during the fifth and last daily session. The objective was to evaluate longterm habituation and novelty-induced recovery processes in the courtship behavior of guinea pigs. We used pregnant females as social stimuli in order to control for possible changes in receptivity contingent on female contacts with a mate. In female guinea pigs, estrus is terminated by copulation, probably by a factor contained in the male's ejaculate (13). Pregnant females were assumed to provide the relatively constant social stimulation required for the assessment of habituation-recovery effects on courtship behavior.

Four adult males and four adult pregnant females in the middle to the late phase of pregnancy from the guinea pig colony of the Department of Experimental Psychology (University of São Paulo) were used. The animals were unfamiliar to each other at the beginning of the experiment and were taken from boxes in which they had been kept in family groups composed of a reproductive female, a reproductive male and their offspring. The animals were housed individually for one week prior to testing. Each male was then randomly paired to a female with which it was tested during four daily $15 \mathrm{~min}$ sessions in a $60 \times 90 \times 30 \mathrm{~cm}$ box. On the fifth day, pairs were randomly rearranged, each male being paired with one of the other three, unfamiliar females.

Sessions were videotaped and the duration of behavioral categories for both males and females was obtained from the videotape records using the EthoLog 2.2 observational software (14). Male courtship categories selected for analysis were: circling (moving in a circle around the female), following the female, investigating (sniffing and licking the female), rumba (performing swinging movements, with or without the purr vocalization) and mounting (mounting the female, with or without copulatory movements). Female courtship categories selected for analysis were: investigating (sniffing and licking the male) and attacking (rebuffing or aggressing the male). Data are reported as percent session time spent performing a category. Since attacking displays were very brief, their frequency instead of percent time was recorded. Since the male 2-female 2 pair remained totally motionless during samemate session 1, this session was discarded and session 2 was taken as their first interaction session.

The results show that, from the first to the second sessions, all male subjects decreased the time allocated to investigating, following and mounting (Figure 1). Rumba and circling did not show a patterned change in duration along the sessions. Percent session time devoted to rumba from sessions 1 to 4 was: $0,1.1,1.1,1.7$ (male 1); 0, 0, 0.2 (male 2); 5.3, 3.2, 3.5, 1.4 (male 3); 3.4, 6.6, 8.6, 2.4 (male 4), respectively. Percent session time devoted to circling was $0.2,0,0,3.4$ 
(male 1); 0, 2.0, 2.0, 0.3 (male 2); 15.9, 1.0, 1.0, 0.9 (male 3); 4.2, 0.9, 0.5, 8.8 (male 4), respectively.

Female switching brought about a recovery of investigating in all males. Males 1, 2 and 3 showed an increase of circling from sessions 4 to 5 and males 1,2 and 4, an increase of following. Male 1 displayed increased levels of mounting (Figure 1).

Females did not show decreases in percent time spent investigating throughout the sessions in which they were exposed to the same male. Percent session time devoted to investigating from sessions 1 to 4 was 4.6, 4.2, 5.7, 2.2 (female 1); 0, 0.7, 1.2, 0.3 (female 2); 3.2, 8.8., 2.7, 2.7 (female 3); 2.3, $2.4,1.5,3.2$ (female 4), respectively. Only female 3 increased investigating when exposed to the novel male in the fifth session (percent session time: 3.0 ).

Attacking frequency by females was low and did not follow an orderly pattern throughout habituation sessions. The frequencies were 1.0, 1.0, 1.0, 0 (female 1); 0, 4.0, 2.0, 1.0 (female 2); 0, 0, 1.0, 1.0 (female 3), and 7.0, 1.0, 1.0, 2.0 (female 4), respectively. Female 2 (frequency: 10.0) and female 4 (frequency: 7.0) showed increased attacking behavior when confronted with a new male in session 5 .

The habituation pattern, as observed by the decrease in investigatory and sexual behavior of males throughout repeated exposure to a female, seems to be robust enough since it occurred in all or most of the animals and in several courtship categories. This cannot be interpreted as being due to a session to session change in female behavior because these changes were not systematic. Another possible interpretation of the decrease in sexual behavior is that it represents the extinction of courting and copulating attempts in a situation in which females do not react with lordosis, or a habituation to courtship resulting from the waning of mate novelty.

Recovery of the courtship performance of males occurred in some categories during the switched-mate session. Such recovery indicates that courtship in guinea pigs may be controlled by the novelty of the female. It may also be taken as an indication that guinea pig males recognize the females with which they interact: increases in courtship and social exploration would not be expected if males did not discriminate the novel female from the familiar one.

The present results agree with many other reports of individual recognition among guinea pigs. There is evidence that both domestic (C. porcellus) and wild (C. aperea) adult guinea pigs are able to recognize famil-
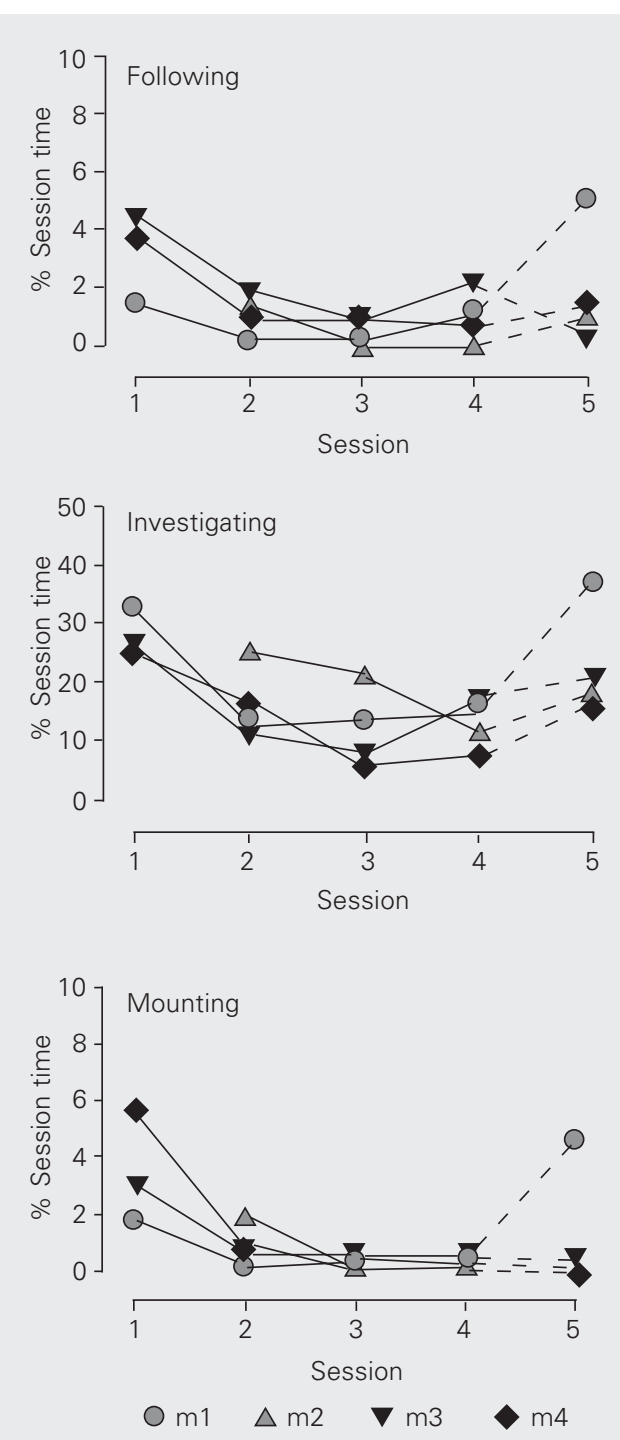

Figure 1. Percent time spent following, investigating and mounting females by male guinea pigs, during 15 -min daily encounters. The same female was presented during sessions 1 to 4 , and a novel female during session 5 (broken lines). The male guinea pigs are identified as $\mathrm{m} 1, \mathrm{~m} 2, \mathrm{~m} 3$ and $\mathrm{m} 4$. 
iar conspecifics (15-18). Beauchamp and Wellington (19) reported that male guinea pigs decreased their investigation of the urine of a female conspecific throughout repeated presentations, even when the first presentation was as short as $2 \mathrm{~min}$ and if the delay to the second presentation was as long as 7 days. Similar habituation-recovery effects have been reported for other rodent species such as hamsters. Repeated exposure of intact and castrated hamsters to a female's vaginal discharge reliably produces habituation of investigatory behavior. Presentation of the odor from a novel female to a habituated male causes a dishabituation-induced increase in investigation (20).

Although not all males displayed a recovery of mounting or rumba behavior towards the switched female, there was a consistent increase in investigating and following the novel female, categories which are included in the normal courtship repertoire of male guinea pigs. The mounting behavior of male 1 elicited by contact with (switched) female 3 indicates that, at least in some cases, full recovery may occur. Female guinea pigs did not display habituation or recovery of investigating in the present experimental context. Attack behavior, which was performed by females 2 and 4, in both the first and fifth sessions, might be under the control of male novelty and also be elicited by the male's investigatory and mounting activity, regardless of the male being familiar or novel. It would be relevant to assess the role of male novelty in female readiness to enter a courtship episode.

Our results indicate the existence in male guinea pigs of a process of habituation/recovery of courtship responses under the control of female novelty. Further studies may indicate whether the influence of female novelty also occurs in socially more complex and naturalistic situations.

\section{Acknowledgments}

We thank Patrícia Monticelli for helpful comments during the preparation of the manuscript.

\section{References}

1. King JA (1956). Social relations of the domestic guinea pigs living under semi-natural conditions. Ecology, 37: 221-228.

2. Berryman JC (1976). Guinea pig vocalizations: their structure, causation and function. Zeitschrift für Tierpsychologie, 41: 80-106.

3. Monticelli P \& Ades C (2001). Acoustic aspects of domestication: vocal signals of alarm and courtship in wild and domestic cavies. Advances in Ethology, 36: 153 (Abstract).

4. Jacobs WW (1976). Male-female associations in the domestic guinea pig. Animal Learning and Behavior, 4: 77-83.

5. Sachser N (1986). Different forms of social organization at high and low population densities in guinea pigs. Behaviour, 97: 253-272

6. Sachser N (1998). Of domestic and wild guinea pigs: studies in sociophysiology, domestication, and social evolution. Naturwissenschaften, 85: 307-317.

7. Sachser N, Durschlag M \& Hirzel D (1998). Social relationships and the management of stress. Psychoneuroendocrinology, 23: 891904.

8. Henessy MB (1999). Social influences on endocrine activity in guinea pigs: studies with comparisons to findings in nonhuman primates. Neuroscience and Biobehavioral Reviews, 23: 687-698.

9. Lisk RD \& Baron $\mathrm{G}$ (1982). Female regulation of mating location and acceptance of new mating partners following mating to sexual satiety: the Coolidge effect demonstrated in the female golden hamster. Behavioral and Neural Biology, 36: 416-421.

10. Johnston RE \& Rasmussen K (1984). Individual recognition of female hamsters by males: role of chemical cues and of the olfactory and vomeronasal systems. Physiology and Behavior, 33: 95-104.

11. Bermant G, Lott DF \& Anderson L (1968). Temporal characteristics of the Coolidge effect in male rat copulatory behavior. Journal of Comparative and Physiological Psychology, 650: 447-452.

12. Pierce JD, Obrien KK \& Dewsbury DA (1992). No effect of familiarity on the Coolidge effect in prairie voles (Microtus ochrogaster). Bulletin of the Psychonomic Society, 30: 325-328.

13. Roy MM, Goldstein KL \& Williams C (1993). Estrus termination following copulation in female guinea pigs. Hormones and Behavior, 27: 397-402.

14. Ottoni EB (2000). EthoLog 2.2: a tool for the transcription and timing of behavior observation sessions. Behavior Research, Methods, Instruments \& Computers, 32: 446-449.

15. Beauchamp GK (1973). Attraction of male guinea pig to conspecific urine. Physiology and Behavior, 10: 589-594.

16. Ruddy LL (1980). Discrimination among colony mates anogenital 
odors by guinea pigs (Cavia porcellus). Journal of Comparative and Physiological Psychology, 94: 767-774.

17. Martin IG \& Beauchamp GK (1982). Olfactory recognition of individuals by male cavies (Cavia aperea). Journal of Chemical Ecology, 8: 1241-1249.

18. Drickamer LC \& Martan J (1984). Odor discrimination and dominance in male domestic guinea pigs. Behavioural Processes, 27: 187-194.
19. Beauchamp GK \& Wellington JL (1984). Habituation to individual odors occurs following brief, widely spaced presentation. Physiology and Behavior, 32: 511-514.

20. Havens MD \& Rose JD (1992). Investigation of familiar and novel chemosensory stimuli by golden hamsters: effects of castration and testosterone replacement. Hormones and Behavior, 26: 505511. 